\title{
Direct synthesis of dimethyl carbonate and propylene glycol using potassium bicarbonate as catalyst in supercritical $\mathrm{CO}_{2}$
}

\author{
Yicun Wen ${ }^{1}$, Rui Zhang ${ }^{*}$, Yu Cang ${ }^{1}$, Jianchao Zhang ${ }^{1}$, Lixiao Liu ${ }^{1}$, Xuhong Guo ${ }^{1}$, Bin Fan ${ }^{2 *}$ \\ ${ }^{1}$ East China University of Science and Technology, State Key Laboratory of Chemical Engineering, Shanghai, 200237, \\ P. R. China \\ ${ }^{2}$ Chinese Academy of Sciences, State Key Laboratory of Environmental Aquatic Chemistry, Research Center for Eco- \\ -Environmental Sciences, Beijing 100085, China \\ "Corresponding authors: e-mail: r.zhang@edust.edu.cn, fanbin@rcees.ac.cn
}

\begin{abstract}
The improved one-pot synthesis of dimethyl carbonate and propylene glycol from propylene oxide, supercritical carbon dioxide, and methanol with potassium bicarbonate as the catalyst has been reported in this paper. As far as we know, it is the first time to use potassium bicarbonate only as the catalyst in the production process which is simple and cheap. Satisfactory conversion rate of propylene oxide and yield of the products could be achieved at the optimized conditions with quite a small amount of by-products. Our new method offers an attractive choice for the production of dimethyl carbonate in large-scale industry efficiently and environmental friendly.
\end{abstract}

Keywords: direct synthesis, dimethyl carbonate, carbon dioxide, potassium bicarbonate, supercritical fluids.

\section{INTRODUCTION}

Because carbon dioxide $\left(\mathrm{CO}_{2}\right)$ is an abundant, inexpensive, and nontoxic biorenewable resource, it is an attractive raw material for incorporation into important industrial processes. $\mathrm{CO}_{2}$ is also attractive as an environmentally friendly chemical reagent, and is especially useful as a phosgene substitute. Then the development of environmentally benign processes utilizing $\mathrm{CO}_{2}$ has become a very attractive topic in recent years ${ }^{1-3}$. The special properties of supercritical fluids (SCFs) give rise to a whole range of utilizations: reaction yields, rates, and selectivity can be adjusted by changing pressure; SCFs (especially $\mathrm{CO}_{2}$ ) can be used as green solvents; mass transfer is improved for heterogeneous reactions due to the obviously increased solubility; and simultaneous reaction and separation may be achieved for some reactions ${ }^{2,4}$

Synthesis of dimethyl carbonate (DMC) using $\mathrm{CO}_{2}$ is one of the promising reactions for the purpose of the development of environmentally benign processes utilizing $\mathrm{CO}_{2}$. DMC is a versatile compound that represents an attractive eco-friendly alternative to both methyl halides (or dimethyl sulfate) and phosgene for methylation and carbonylation processes, respectively. The application of DMC extends to polycarbonate synthesis, carbonylating reagents, polyurethane synthesis, alkylating reagents, octane boosters in gasoline, polar solvents, carbon-particle reducing agents for diesel engines, and so on ${ }^{5}$. Especially, DMC is gaining importance as a safe and environmentally benign alternative for phosgene in some kinds of reactions ${ }^{6}$.

Utilization of DMC in different applications is growing, so effective and clean synthesis routes are of great importance. Until now, there are two basic routes to synthesis $\mathrm{DMC}^{7,8}$. The first one is the methanolysis of phosgene with toxic gas which is harmful to the environment. Another way is the non-phosgene route which is based on the oxidative carbonylation of methanol. However, there are several obvious disadvantages of this route: safety and environmental concern due to the possible leakage of carbon monoxide; and the process being pricy due to the noble metal catalyst. So the exploration of new clean ways for DMC synthesis is urgent.

Direct synthesis routes of DMC from transesterification of cyclic carbonates is a new proposal to this problem which employs two original chemicals, $\mathrm{CO}_{2}$ and methanol, with inorganic bases ${ }^{9}$, organometallic complexes ${ }^{\mathbf{1 0}}$, and modified metallic oxide ${ }^{11}$ as catalysts. The great advantage of this method is its facility. However, the conversion rate of this reaction is very low due to the thermodynamic limitations. The DMC can also be synthesized from $\mathrm{CO}_{2}$ and ortho-esters ${ }^{12}$ or acetals ${ }^{13}$. The disadvantage of this route is the high cost of the raw materials.

The two-step synthesis of DMC from epoxides, $\mathrm{CO}_{2}$, and methanol is another effective non-phosgene method (Scheme 1) which produces a cyclic carbonate ${ }^{13-15}$. Different solid catalysts have been systematically studied for the two-step synthesis of DMC, and satisfactory results have been obtained. However, the major problems of this process are the decompsotion of the catalyst and the hydrolysis of the carbonate.

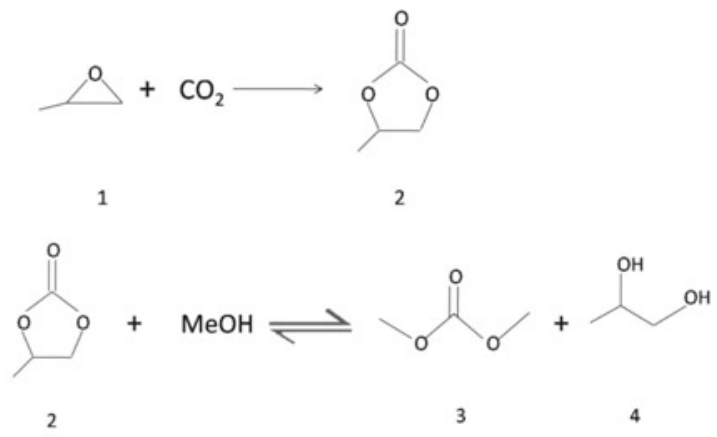

Scheme 1. Two-step synthesis of DMC from epoxides, $\mathrm{CO}_{2}$, and methanol

The one-pot reaction shown in Scheme 2 is a much facile process because it can eliminate the separation process after the first reaction step (Scheme 1). Unfortunately, this method is not successful because of the large amount of the by-products produced from the alcoholysis of epoxides (Scheme 2, second line) ${ }^{\mathbf{1 6 - 1 8}}$. Therefore, the key to carry out the one-pot reaction is that the catalyst should be active for both the reactions 


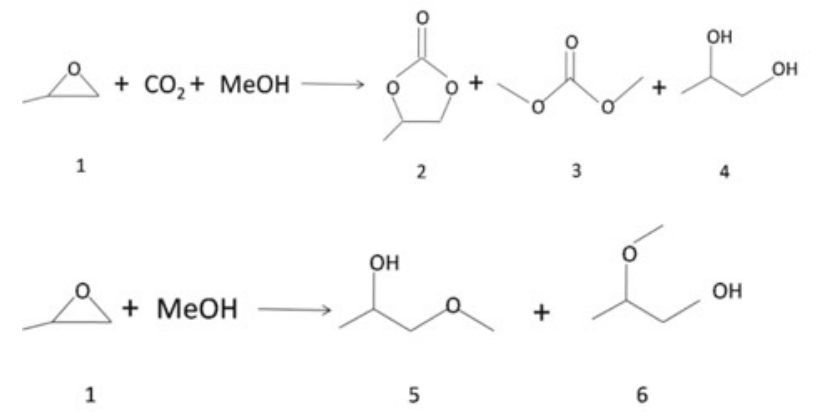

Scheme 2. One-pot reaction of DMC from epoxides, $\mathrm{CO}_{2}$, and methanol

in Scheme 1, while it should not be active to side reactions like alcoholysis of epoxides.

In this work, we investigate the direct one-pot synthesis of DMC from propylene oxide (PO), supercritical $\mathrm{CO}_{2}$ $\left(\mathrm{SC} \mathrm{CO}_{2}\right)$, and methanol with potassium bicarbonate $\left(\mathrm{KHCO}_{3}\right)$ as catalyst. The results indicate that inorganic salt $\mathrm{KHCO}_{3}$ is an effective catalyst and it may also work as a dry agent to shift the equilibrium of the reaction in Scheme 1 (second line). High conversion rate of PO and yields of DMC and propylene glycol (PG) can be achieved. $\mathrm{SC} \mathrm{CO}_{2}$ acts as both the reactant and the solvent, and this process has special advantages. For example, compared with the two-step process, the separation process after the first reaction step is avoided; the reaction is conducted in homogenous supercritical conditions, where non-corrosive $\mathrm{CO}_{2}$ is the main component in the reaction mixture, which prolongs the life of the catalysts. Compared with the previous result ${ }^{[19]}$ which employs potassium carbonate $\left(\mathrm{K}_{2} \mathrm{CO}_{3}\right)$ as catalyst in the process, we can get the conclusion that the weak base is a better catalyst for the direct synthesis of DMC and PG.

\section{EXPERIMENTAL SECTION}

$\mathrm{KHCO}_{3}, \mathrm{~K}_{2} \mathrm{CO}_{3}$, magnesium oxide $(\mathrm{MgO}), \mathrm{N}, \mathrm{N}$-dimethylformamide (DMF) and anhydrous methanol were produced by Beijing Chemical Reagent Factory (A. R. Grade). Propylene oxide was supplied by Shanghai Chemical Reagent Factory (A. R. Grade). $\mathrm{CO}_{2}$ (>99.95\%) was purchased from Beijing Analytical Instrument Factory. Methanol was dried with $4 \AA$ molecular sieves. All the other chemicals were used without further purification.

The employed apparatus of synthesis DMC was shown in Figure 1. A stainless steel batch reactor (high-pressure cell) of $17.4 \mathrm{ml}$ was used. The main components were a reactor, a constant temperature oil bath, a pressure gauge, a $\mathrm{CO}_{2}$ pump, a magnetic stirrer, and a cold trap. The temperature fluctuation of the air bath was $\pm 0.5 \mathrm{~K}$ which was controlled by a PID temperature controller made by Beijing Tianchen Electronic Company (Model SX/A-1). The pressure gauge composed a pressure transducer (FOXBORO/ICT, model 93) and an indicator; its accuracy level was $\pm 0.05 \mathrm{MPa}$ in the pressure range of 0-20 MPa.

In a typical experiment, the desired amount of catalyst, $\mathrm{PO}$, and methanol were loaded into the reactor. Suitable amount of $\mathrm{CO}_{2}$ was then charged into the reactor with a $\mathrm{CO}_{2}$ sample bomb, and the amount of $\mathrm{CO}_{2}$ charged was calculated from the weight difference of the sample

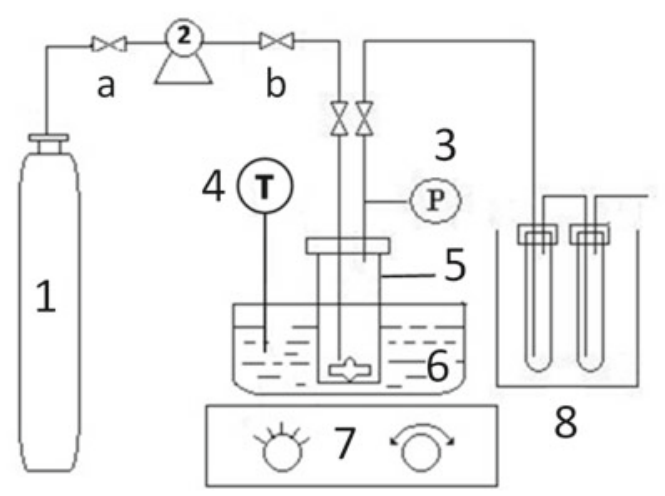

Figure 1. Schematic diagram of the apparatus for DMC synthesis. 1 - gas cylinder, 2 - high-pressure syringe pump, 3 - pressure gauge, 4 - temperature controller, 5 - reactor (high-pressure cell), 6 - oil bath, 7 - magnetic stirrer, 8 - cold trap, a, b - valves

bomb before and after charging. Then the reactor was placed into a temperature oil bath with a constant stir rate. After a certain time, the reactor was cooled down to $323.15 \mathrm{~K}$, and then $\mathrm{CO}_{2}$ was released slowly passing through the cold trap with DMF as an absorbent. The liquid chemicals in the reactor were extracted in situ by $\mathrm{SC} \mathrm{CO}_{2}$ at $12 \mathrm{MPa}$. Experiments showed that all the reactants and products were collected in the cold trap, and about $80 \mathrm{~g}$ of $\mathrm{CO}_{2}$ was required to extract all liquid chemicals. Experiments proved that the amount of reactants and products entrained by $\mathrm{CO}_{2}$ was negligible. The catalyst was left in the reactor, because it was not soluble in $\mathrm{SC} \mathrm{CO}_{2}$. The liquid mixture in the reactor was analyzed by gas chromatography (Agilent 4890D, Agilent Technologies Inc.) with an Innowax capillary column $(30 \mathrm{~m} \times 0.252 \mathrm{~mm} \times 0.25 \mu \mathrm{m})$ and a FID detector.

\section{RESULTS AND DISCUSSION}

In this work, we investigate the one-pot synthesis of DMC from $\mathrm{PO}, \mathrm{CO}_{2}$, and methanol with $\mathrm{KHCO}_{3}$ as catalyst. The DMC synthesis process actually includes three reactions as following: the first one is $\mathrm{CO}_{2}$ reacts with $\mathrm{PO}$ to produce cyclic carbonate (propylene carbonate, $\mathrm{PC}$ ); and the second one is the tranesterification of methanol with PC to obtain DMC and PG. The third one is a side reaction which is the tranesterification of methanol with PO with alcohol 5 (on Scheme 2) and 6 (on Scheme 2) as the products. The basic issue is how to obtain high conversions while avoiding thermodynamic restriction and the effect of reaction time is critically important.

According to the previous result about the direct synthesis of DMC and PG from PO, $\mathrm{CO}_{2}$, and methanol with potassium carbonate as catalyst ${ }^{19}$, we know that increasing the feed molar ratio of methanol to PO can improve the yield of DMC, but the percentage of the methanol reacted decreases with the ratio increasing. The yield in this work is defined as follows: Yield $=$ (moles of product)/(moles of epoxides added). The conversion is defined as the ratio of the moles of the reactant reacted to the moles of the reactant taken initially. The 1:4:10 molar ratio of $\mathrm{PO}: \mathrm{CH}_{3} \mathrm{OH}: \mathrm{CO}_{2}$ is the best condition for the system under which the content of DMC in the liquid mixture after reaction is largest. Considering that the properties of $\mathrm{K}_{2} \mathrm{CO}_{3}$ and $\mathrm{KHCO}_{3}$ are quiet similar, 
the same molar ratio of the reactants is employed in this work. Figure 2 shows the dependence of the yield of DMC on the reaction time. It can be seen that the conversion of $\mathrm{PO}$ almost reaches $100 \%$ after 4 hours and the yield of DMC up to constant about $20 \%$. It means that the reaction reaches equilibrium after about $4 \mathrm{~h}$. In the following, the results with a reaction time of 4 hours are discussed without special indicated.

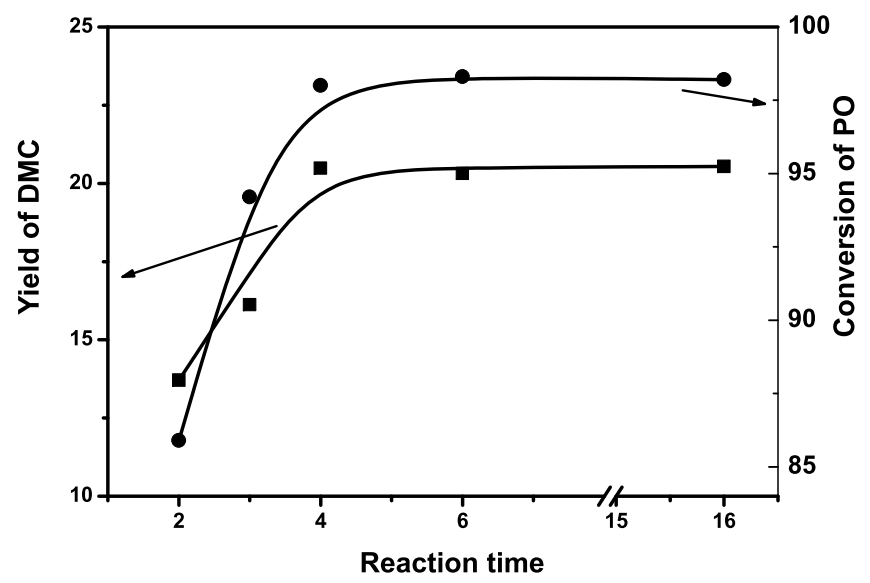

Figure 2. The PO conversion and DMC yield on reaction time. (The reaction condition: temperature 413.15 K, pressure $12 \mathrm{Mpa}$, the molar ratio of PO: $\mathrm{CH}_{3} \mathrm{OH}: \mathrm{CO}_{2}: \mathrm{K}_{2} \mathrm{CO}_{3}=1: 4: 10: 0.065$, the amount of $\mathrm{PO}$ in the reactor is $5 \mathrm{mmol}$.)

Up to now, the mature route to synthesize DMC using epoxides, $\mathrm{CO}_{2}$ and methanol may be the Bhanage et al. ${ }^{17}$, who explored a two-step synthesis route using various basic metal oxide catalysts. They found that $\mathrm{MgO}$ was the best catalyst among the catalysts they used. They also carried out the direct synthesis using $\mathrm{Mg}$ contained catalysts, and they found that large amounts of by-products were produced, which were formed by methanolysis of epoxides ${ }^{\mathbf{1 4 , 1 7}}$. We also conduct the direct synthesis using this catalyst $(\mathrm{MgO})$ under the reaction condition of this work, the yield of DMC is as low as $8.24 \%$ when $\mathrm{PO}$ is used as raw material, and a significant amount by-products is produced, which can be known from entry 1 in Table 1 . Table 1 also shows the results of $\mathrm{K}_{2} \mathrm{CO}_{3}$ and $\mathrm{KHCO}_{3}$ as catalyst with the 1:10:0.065 ratio of PO: $\mathrm{CO}_{2}$ :catalyst indicate that both of them are effective catalyst for the direct synthesis of DMC. The data in Table 1 indicates that the synthesis is a series of reactions involving a cyclic carbonate intermediate.

Molar ratio of methanol:PO is a critically important factor for the results as shown in Table 1, as well as the hydrolysis ability of catalyst. The side reaction at a lower ratio of methanol:PO with $\mathrm{KHCO}_{3}$ as a relatively weaker base catalyst is under its unfavorable condition. In other words, with the $4: 1$ molar ratio of methanol:PO, the side reaction of the tranesterification of methanol with PO to the alcohol 5 and 6 (on Scheme 2) is not active. For example, the total yield of $(5+6)$ is $11.94 \%$ and $10.16 \%$ for $\mathrm{K}_{2} \mathrm{CO}_{3}$ and $\mathrm{KHCO}_{3}$ respectively. (Entry 2 and 3) However, increasing the molar ratio of methanol:PO activates the side reaction and then the total yield of alcohol $(5+6)$ is increased obviously. For entry 3, 5, and 7 , the total yield of alcohol $(5+6)$ is $10.16 \%, 24.69 \%$ and $34.87 \%$ respectively with $\mathrm{KHCO}_{3}$ as catalyst. The reason may be due to the over-alcoholysis of $\mathrm{PO}$ with too much methanol. In other words, compare $\mathrm{K}_{2} \mathrm{CO}_{3}$ with $\mathrm{KHCO}_{3}$ as catalyst, we know that with a suitable ratio of methanol:PO, $\mathrm{KHCO}_{3}$ will result in a slightly higher yield of DMC (Entry 2 and 3); while increasing the ratio of methanol:PO, higher yield of DMC can be obtained with $\mathrm{K}_{2} \mathrm{CO}_{3}$ which can prevent the over-alcoholysis of $\mathrm{PC}$ due to its higher hydrolysis ability.

\section{CONCLUSIONS}

In brief, the results indicate both $\mathrm{K}_{2} \mathrm{CO}_{3}$ and $\mathrm{KHCO}_{3}$ are high efficient catalyst, while the yield of $\mathrm{KHCO}_{3}$ is slightly higher. The conversion rate of $\mathrm{PO}$ is high while the yield of DMC can be up to $30 \%$, and the amount of by-products (alcohol 5 and 6) is small which can be decreased to $10 \%$ of the final products. $\mathrm{SC} \mathrm{CO}_{2}$ acts as both reactant and solvent. This route may play an important role in the large-scale production of DMC due to its great advantages, for example, it is facile, the raw materials are cheap, and the amount of the by-products is small.

\section{ACKNOWLEDGEMENTS}

This work is supported by National Natural Science Foundation of China (21004021, 21374029, 51278484), the Fundamental Research Funds for the central universities (WA1014007, 222201313011), Shanghai Education Innovation Key Project (14ZZ061), Chemical engineering national key laboratory open subject SKL-ChE-11CO2, The start funding of East China University of Science and Technology YA0142119. We also appreciate the financial support from China Scholarship Council.

Table 1. The DMC synthesis results with different catalysts*

\begin{tabular}{|c|c|c|c|c|c|c|c|}
\hline \multirow{2}{*}{ Entry } & \multirow{2}{*}{ Catalyst } & \multirow{2}{*}{$\begin{array}{l}\text { MeOH:PO } \\
\text { [molar ratio] }\end{array}$} & \multirow{2}{*}{ PO Conv [\%] } & \multicolumn{4}{|c|}{ Yield [\%] } \\
\hline & & & & DMC & $\mathrm{PC}$ & $P G$ & $5+6$ \\
\hline 1 & $\mathrm{MgO}$ & $4: 1$ & 89.23 & 8.24 & 32.5 & 10.21 & 40.26 \\
\hline 2 & $\mathrm{~K}_{2} \mathrm{CO}_{3}$ & $4: 1$ & 98.27 & 20.31 & 33.84 & 34.20 & 11.94 \\
\hline 3 & $\mathrm{KHCO}_{3}$ & $4: 1$ & 99.53 & 23.10 & 35.46 & 32.06 & 10.16 \\
\hline 4 & $\mathrm{~K}_{2} \mathrm{CO}_{3}$ & $10: 1$ & 98.00 & 30.48 & 22.09 & 25.58 & 23.94 \\
\hline 5 & $\mathrm{KHCO}_{3}$ & $10: 1$ & 96.87 & 16.84 & 32.17 & 27.22 & 24.69 \\
\hline 6 & $\mathrm{~K}_{2} \mathrm{CO}_{3}$ & $15: 1$ & 98.39 & 19.55 & 30.11 & 21.87 & 29.07 \\
\hline 7 & $\mathrm{KHCO}_{3}$ & $15: 1$ & 97.41 & 16.29 & 25.15 & 22.95 & 34.87 \\
\hline
\end{tabular}

* The reaction condition: temperature $413.15 \mathrm{~K}$, the molar ratio of $\mathrm{PO}: \mathrm{CO}_{2}$ : catalyst $=1: 10: 0.065$, the amount of $\mathrm{PO}$ in the reactor is $5 \mathrm{mmol}$. 


\section{LITERATURE CITED}

1. Darensbourg, D.J. (2007). Making Plastics from Carbon Dioxide: Salen Metal Complexes as Catalysts for the Production of Polycarbonates from Epoxides and $\mathrm{CO}_{2}$. Chem. Rev. 107 (6), 2388-2410. DOI:10.1021/cr068363q.

2. Jessop, P.G., Ikariya, T. \& Noyori, R. (1999). Homogeneous Catalysis in Supercritical Fluids. Chem. Rev. 99 (2), 475-493. DOI: $10.1021 /$ cr970037a.

3. Baiker, A. (1999). Supercritical fluids in heterogeneous catalysis. Chem. Rev. 99 (2), 453-474. DOI: 10.1021/cr970090z.

4. Darr, J.A. \& Poliakoff, M. (1999). New directions in inorganic and metal-organic coordination chemistry in supercritical fluids. Chem. Rev. 99 (2), 495-541. DOI: 10.1021/cr970036i.

5. Tundo, P. \& Selva, M. (2002). The chemistry of dimethyl carbonate. Acc. Chem. Res. 35 (9), 706-716. DOI: 10.1021/ $\operatorname{ar} 010076 \mathrm{f}$.

6. Fukuoka, S., Kawamura, M., Komiya, K., Hachiya, H., Hasegawa, K., Aminaka, M., Okamoto, H., Fukawa, I. \& Konno, S. (2003). A novel non-phosgene polycarbonate production process using by-product $\mathrm{CO} 2$ as starting material. Green. Chem. 5, 497-507. DOI: 10.1039/B304963A.

7. King, S.T. (1997). Oxidative Carbonylation of methanol to dimethyl carbonate by solid-state ion-exchanged $\mathrm{CuY}$ catalysts. Catal. Today 33, 173-182. DOI: 10.1016/S0920-5861(96)00118-6.

8. Sato, Y., Yamamoto, T. \& Souma, Y. (2000). Poly(pyridine-2,5-diyl)- $\mathrm{CuCl}_{2}$ catalyst for synthesis of dimethyl carbonate by oxidative carbonylation of methanol: catalytic activity and corrosion influence. Catal. Lett. 65, 123-126. DOI: 10.1023/A:1019033725260.

9. Fujita, S.I., Bhanage, B.M., Ikushima, Y. \& Arai, M. (2001). Synthesis of dimethyl carbonate from carbon dioxide and methanol in the presence of methyl iodide and base catalysts under mild conditions: effect of reaction conditions and reaction mechanism. Green. Chem. 3 (2), 87-91. DOI: 10.1039/B100363L.

10. Choi, J.C., Sakakura, T. \& Sako, T. (1999). Reaction of dialkyltin methoxide with carbon dioxide relevant to the mechanism of catalytic carbonate synthesis. J. Am. Chem. Soc. 121, 3793-3794. DOI: 10.1021/ja9900499.

11. Tomishige, K. \& Kunimori, K. (2002). Catalytic and direct synthesis of dimethyl carbonate starting from carbon dioxide using $\mathrm{CeO}_{2}-\mathrm{ZrO}_{2}$ solid solution heterogeneous catalyst: effect of $\mathrm{H}_{2} \mathrm{O}$ removal from the reaction system. Appl. Catal. A: Gen. 237, 103-109. DOI: 10.1016/S0926-860X(02)00322-8.

12. Isaacs, N.S., O'Sullivan, B. \& Verhaelen, C. (1999) High pressure routes to dimethyl carbonate from supercritical carbon dioxide. Tetrahedron 55, 11949-11956. DOI: 10.1016/ S0040-4020(99)00693-6.

13. Sakakura, T., Choi, J.C., Saito, Y., Masuda, T., Sako, Y., Masuda, T., Sako, T. \& Oriyama, T. (1999). Metal-catalyzed dimethyl carbonate synthesis from carbon dioxide and acetals. J. Org. Chem. 64, 4506-4508. DOI: 10.1021/jo990155t.

14. Bhanage, B.M., Fujita, S.I., Ikushima, Y., Torii, K. \& Arai, M. (2003). Synthesis of dimethyl carbonate and glycols from carbon dioxide, epoxides and methanol using heterogeneous $\mathrm{Mg}$ containing smectite catalysts: effect of reaction variables on activity and selectivity performance. Green. Chem. 5, 71-75. DOI: 10.1039/B207750G.

15. Bhanage, B.M., Fujita, S.I., He, Y.F., Ikushima, Y., Shirai, M., Torii, K. \& Arai, M. (2002). Concurrent Synthesis of Dimethyl Carbonate and Ethylene Glycol via Transesterification of Ethylene Carbonate and Methanol Using Smectite Catalysts Containing Mg and/or Ni. Catal. Lett. 83, 137-141. DOI: $10.1023 / \mathrm{A}: 1021065409888$.

16. Sakakura, T. \& Kohno, K. (2009). The synthesis of organic carbonates from carbon dioxide. Chem. Comm. 11. 1312-1330. DOI: $10.1039 / b 819997 \mathrm{c}$.

17. Bhanage, B.M., Fujita, S.I., Ikushima, Y. \& Arai, M. (2001). Synthesis of dimethyl carbonate and glycols from carbon dioxide, epoxides, and methanol using heterogeneous basic metal oxide catalysts with high activity and selectivity. Appl. Catal. A: Gen. 219 (1-2), 259-266. DOI: 10.1016/S0926860X(01)00698-6.

18. Chang, Y.H., Jiang, T., Han, B.X., Liu, Z.M., Wu, W.Z., Gao, L., Li, J.C., Gao, H.X., Zhao, G.Y. \& Huang, J. (2004). One-pot synthesis of dimethyl carbonate and glycols from supercritical $\mathrm{CO}_{2}$, ethylene oxide or propylene oxide, and methanol. Appl. Catal. A: Gen. 263 (2), 179-186. DOI: 10.1016/j.apcata.2003.12.012.

19. Fan, B., Qu, B., Chen, Q.C., Wen, Y.C., Cai, L. \& Zhang, R. (2011). An improved one-pot synthesis of dimethyl carbonate from propylene oxide, $\mathrm{CO}_{2}$ and methanol. J. Chem. Res. 35, 654-656. DOI: 10.3184/174751911X13192908398731. 